\title{
Immunocytochemical study of the interaction of soybean trypsin inhibitor with rat intestinal mucosa
}

\author{
PATRICIA A. WILSON ${ }^{1}$, R. N. MELMED ${ }^{2}$, MAGDOLNA M. V. HAMPE ${ }^{3}$, \\ AND S. J. HOLT ${ }^{4}$ \\ From the Courtauld Institute of Biochemistry, Middlesex Hospital Medical School, London
}

SUMMARY To investigate further the cause of the pancreatic enlargement induced by orally ingested soybean trypsin inhibitor (STI), antibodies raised against STI and purified by affinity chromatography were used to localise dietary STI in the rat gut by fluorescent immunocytochemical methods. This technique permitted the clear intracellular demonstration of STI in the ileal mucosa of suckling rats. However, in adult rats no entry of STI into mucosal cells of the small intestine could be demonstrated, it being confined to the luminal surface of the mucosa. Although the passage of STI into and across the adult intestinal mucosa could not be excluded through the use of this technique, the results are consistent with an intraluminal mode of action of STI as suggested by Green and Lyman (1972) -namely, that the pancreatic enlargement caused in sensitive species results from the inhibition of trypsin (which acts as the physiological inhibitor of the mucosal secretion of pancreotrophic hormones), thus resulting in the uninhibited secretion of these hormones.

Continued administration of STI to rats causes enlargement of the pancreas (Booth et al., 1960; Rackis, 1965; Melmed and Bouchier, 1969), particularly in young and suckling rats, and this has now been shown to be due to both hypertrophy and hyperplasia of the exocrine pancreas (Melmed et al., 1976).

The mechanism of action of STI on the pancreas is, however, not clearly understood. It is generally thought that the presence of the inhibitor in the intestinal lumen mediates the release of a factor, presumably the hormone pancreozymin-cholecystokinin, which, in turn, acts on the pancreas (Lyman and Lepkovsky, 1957; Khayambashi and Lyman, 1969; Melmed and Bouchier, 1969). To release such a factor, the STI may act indirectly, simply by removing or blocking trypsin activity (Green and Lyman, 1972). Alternatively, it is possible that STI

'Present address: Division of Animal Physiology, C.S.I.R.O., Ian Clunies Ross Animal Research Laboratory, P.O. Box 239, Blacktown, N.S.W., Australia, 2148.

'Present address: Department of Medicine B, Hadassah University Hospital, P.O. Box 499, Jerusalem, Israel.

${ }^{3}$ Present address: Instituto de Biociencias, Universidade Federal do Rio Grande do Sul, Pôrto Alegre, R.G.S., Brazil.

Address for reprint requests: S. J. Holt, Courtauld Institute, Middlesex Hospital, London W1P 5PR, UK.

Received for publication 3 November 1977 molecules enter the intestinal mucosal cells (particularly the scattered hormone-containing cells) and thereby mediate a response, as it has been established that the intestine of both adult rats (Fisher, 1967; Warshaw et al., 1974) and suckling rats (Cornell and Padykula, 1969) are capable of absorbing active intact proteins, or of transferring them via the lymphatic to the blood stream (Warshaw et al., 1974) where they may then act on the target organ directly.

The following investigations were therefore undertaken in an attempt to define the nature of the interaction between STI and the rat intestine, using immunocytochemical procedures to locate STI in the gastrointestinal tract of both adult and suckling animals. The possible influence of prolonged feeding of a soybean diet on the subsequent interaction between STI and the intestine was also investigated.

\section{Methods}

\section{ANIMALS AND DIET}

Male albino Wistar rats (Courtauld Institute inbred strain) were fed a standard powdered Oxoid 41B diet (W. Lillico \& Son, Wonham Mill, Betchworth, Surrey, UK) either alone ('normal' diet), or supplemented with an equal weight of raw soybean flour ('test' diet) or of heated soybean flour ('control' diet). Both raw soybean flour (Diasoy) and heated soybean flour in which the STI has been inactivated (Soyolk) 
were obtained from Soya Foods Ltd, London, UK. The basal Oxoid 41B diet contains no STI. The rats were put on the diets at $90 \mathrm{~g}$ body weight and fed ad libitum for at least eight weeks before study.

Suckling rats, 15 days old, were taken from a mother fed on the normal diet.

\section{SOYBEAN TRYPSIN INHIBITOR}

As preliminary experiments showed that STI was only weakly antigenic, and in view of the high cost of purified inhibitor, the STI used for infusions or injections was a partially purified powder with an assayed activity of 9240 BAEE units of inhibition $/ \mathrm{mg}$ of material. However, as described below, chromatographically pure STI, having 20000 BAEE units of inhibition/mg, was used for affinity column purification of the antibody. Both grades of STI were obtained from Miles Laboratories Ltd, Stoke Poges, Slough, Berks, UK.

\section{PREPARATION OF ANTISERUM TO STI}

This was obtained by immunising five New Zealand white rabbits. For injection, the STI $(20 \mathrm{mg})$ was completely dissolved in $0.5 \mathrm{ml}$ saline $(0.9 \% \mathrm{w} / \mathrm{v})$ by adding a drop of $0.5 \mathrm{M}$ sodium bicarbonate buffer, pH 9.0. This solution was then emulsified with an equal volume of complete Freund's adjuvant (Difco Laboratories, Michigan, USA) and doses of $0.5 \mathrm{ml}$ were injected intramuscularly into both hind legs of each rabbit-(that is, $20 \mathrm{mg}$ antigen/rabbit). Additional booster injections of antigen $(4 \mathrm{mg} / \mathrm{rabbit})$ were given two weeks after the initial injection, and thereafter at six day intervals. Blood samples were taken during the course of the injection and tested for the presence of antibodies against the antigen by the double immunodiffusion method (Ouchterlony, 1968). After nine weeks, the antiserum gave a strong precipitin reaction, and the rabbits were then bled completely to obtain sufficient serum for the isolation of STI antibodies.

\section{PURIFICATION OF ANTIBODY}

In spite of the fact that STI was only weakly antigenic, the high doses of STI used resulted in a strong immune response. Double immunodiffusion of the whole antiserum against the antigen resulted in at least eight precipitin lines of varying intensity and affinity (Fig. 1A). However, when the antiserum was cross-reacted against the highly purified STI, the precipitin lines were fewer and better resolved (Fig. 1B). On this basis, highly specific STI-antibodies were isolated from the antiserum by affinity chromatography by absorbing them on to purified STI bound to Sepharose, followed by elution of the antibodies from the affinity column.

The STI was coupled to Sepharose 4B (Pharmacia

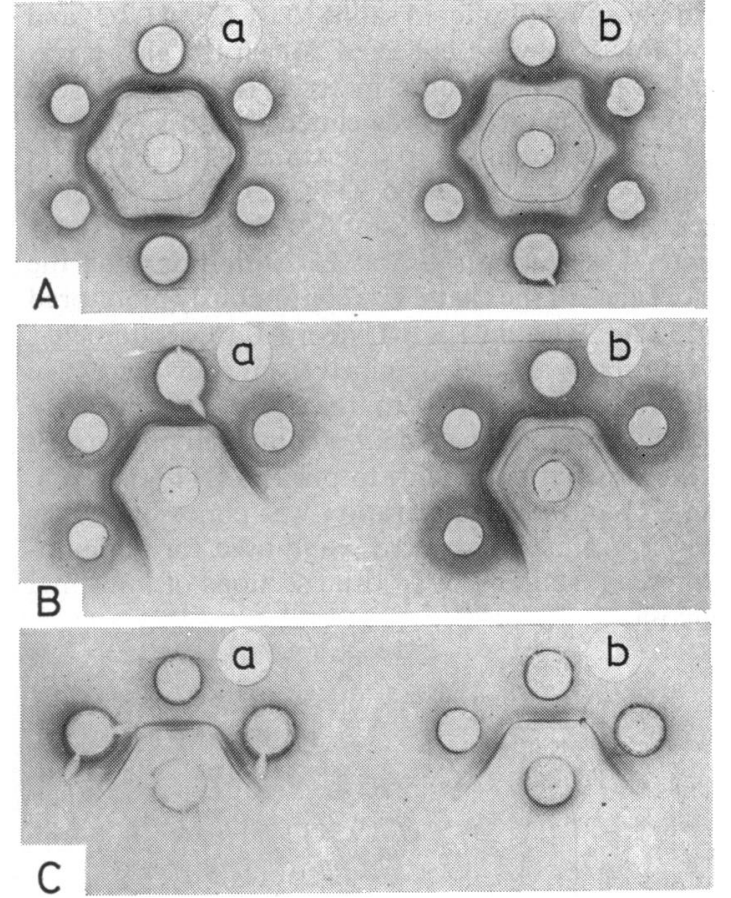

Fig. 1 A: double immunodiffusion in agar. Partially purified STI is in the centre well $(a: 5 \mathrm{mg} / \mathrm{ml}$ saline, $b: 10 \mathrm{mg} / \mathrm{ml}$ ). Outer wells contain antisera. At least eight precipitin lines were produced; those of weak affinity antibodies were better defined at the higher antigen concentration. B: STI-antiserum cross-reacted against highly purified STI (centre well-a: $5 \mathrm{mg} / \mathrm{ml}$ saline, $b: 10 \mathrm{mg} / \mathrm{ml}$ ). At least five precipitin lines were present. C: STI-antibodies present in the combined antibody fractions obtained from four successive applications of antiserum to the affinity chromatography column. The antibody fraction is in the outer wells, and highly purified STI (a: $5 \mathrm{mg} / \mathrm{ml}$ saline, $b: 10 \mathrm{mg} / \mathrm{ml}$ ) is in the centre well.

Fine Chemicals AB, Uppsala, Sweden) by the cyanogen bromide method (Porath et al., 1967) as follows. The Sepharose 4B (14 ml) was treated with freshly prepared aqueous cyanogen bromide (50 $\mathrm{mg} / \mathrm{ml})(11 \mathrm{ml})$ and then highly purified STI $(100 \mathrm{mg})$ was added. After gentle agitation at $4^{\circ} \mathrm{C}$ for 20 hours, the product was thoroughly washed with cold phosphate-buffered saline $(0.01 \mathrm{M}, \mathrm{pH} 7 \cdot 2)$. From the optical density at $280 \mathrm{~nm}$ of the washings it was estimated that $63 \%$ of the STI remained bound to the Sepharose (4.5 mg STI/ml Sepharose). The STISepharose was then layered on to the top of a Sephadex G25 (medium) column $(1.5 \times 30 \mathrm{~cm})$ and the combined column equilibrated with phosphatebuffered saline. Antiserum ( $7 \mathrm{ml}$ ) was then applied to the column. The combined column was eluted 
with phosphate-buffered saline ( $0.01 \mathrm{M}, \mathrm{pH} 7 \cdot 2)$ and $3 \mathrm{ml}$ fractions were collected. When the eluate was free from UV-absorbing material (unbound serum fractions), the column was eluted with $0.1 \mathrm{M}$ acetic acid (HAc) containing $10 \%$ dioxane (Hill, 1972), and $2 \mathrm{ml}$ fractions collected (Fig. 2). The material released contained STI-antibodies in a $\mathrm{pH} 7 \cdot 1$ eluate. The elution rate was $25-30 \mathrm{ml} /$ hour and the absorbance of the eluate was continuously monitored at $254 \mathrm{~nm}$ with an LKB Uvicord I absorptiometer. STI-antibody eluates obtained from four successive antiserum applications to the same column were pooled. The combined eluates contained all but one of the original antibodies to purified STI (Fig. 1C). The STI-antibody preparation was concentrated by dialysis against solid sucrose and used for immunofluorescent staining of cryostat sections of intestinal mucosa.

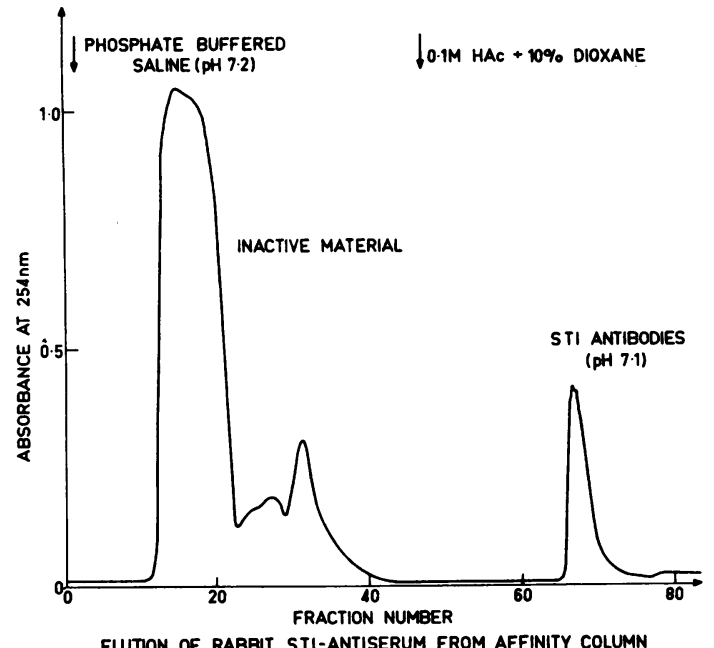

Fig. 2 Chromatography of rabbit antiserum on a column of STI-Sepharose 4B layered above a Sephadex G25 (medium) column $(1.5 \times 30 \mathrm{~cm})($ see p. 261 for details $)$.

This purification of the STI-antibodies successfully removed the non-specific fluorescence which was seen in preliminary staining trials with STI antiserum extracted with rat liver powder as in conventional staining methods (Nairn, 1969).

IMMUNOFLUORESCENCE

Adult rats which had been maintained on the test or control diets (two per group) were killed at 09.00 hours-that is, soon after they had ceased feeding. Samples of duodenum and jejunum were taken for immunofluorescence study.

Alternatively, adult rats on normal, test, and control diets were fasted for 18 hours, then given
$4 \mathrm{ml}$ saline $(0.9 \% \mathrm{w} / \mathrm{v})$ with or without partially purified STI $(150 \mathrm{mg} / \mathrm{ml})$ via a stomach tube. Two animals were used for each group. Samples of duodenum, jejunum, and ileum were removed $5 \cdot 5$ hours after feeding. Samples were also taken from an adult rat on normal diet which had been starved for the entire period.

In further experiments, suckling rats were fasted for 2.5 hours, then given $1 \mathrm{ml}$ saline (two rats) or partially purified STI (two rats, $50 \mathrm{mg} / \mathrm{ml}$ ) via a stomach tube. Samples of jejunum and ileum were removed after six hours. Samples were also taken from a suckling rat starved for the entire period.

The intestinal samples were opened longitudinally, washed in saline, flattened, and then made up into compact rolls. The tissues were frozen in 2-methylbutane (BDH Chemicals Ltd, Poole, Dorset, UK) at $-70^{\circ} \mathrm{C}$. Frozen sections $(4 \mu \mathrm{m}$ thick) were cut at $-15^{\circ} \mathrm{C}$ on a cryostat (Bright Instrument Co. Ltd, Huntingdon, UK) and the slides air-dried at room temperature for one hour. The sections were then treated with the STI-antibody preparation for $\mathbf{3 0}$ minutes, washed with Coons buffer ( $\mathrm{pH} \mathrm{7.0)}$ for 30 minutes, then stained for 30 minutes with fluorescein-labelled anti-rabbit immunoglobulin (Wellcome Reagents Ltd, Beckenham, UK) and rewashed with Coons buffer for 30 minutes. For control staining, additional sections were treated with STI-antibody which had been absorbed with STI $(60 \mathrm{mg}$ partially purified STI/ml antibody preparation), then stained with fluorescent antirabbit immunoglobulin, or sections were treated with fluorescent anti-rabbit immunoglobulin alone. The sections were mounted in glycerol (seven parts) mixed with $0.2 \mathrm{M}$ glycine buffer, $\mathrm{pH} 8.6$ (three parts), and examined by ultra-violet fluorescence microscopy, using a Leitz Ortholux microscope with incident UV illumination and photographed on Kodak Tri-X Pan film (ASA 400).

\section{Results}

LOCALISATION OF STI IN INTESTINAL TRACT In the rats fed on test or control diets, the duodenal and jejunal samples contained slight traces of food in the intestinal lumen and this food showed intense positive fluorescence only in the test animals. However, in these animals very little fluorescence was detected around the villi or in the crypts of either the duodenum or jejunum. There was no fluorescence in samples from animals on control diets, and control staining of the various tissues also gave negative results.

Rats reared on normal diet and then fed STI showed marked fluorescence in the lumen of the duodenum, jejunum, and ileum, and particularly 
where food had collected around the villi (Figs. 3, 4). The brush border of the intestine, especially in the ileum, was positively fluorescent (Fig. 4). Fluorescence was not detected in the cytoplasm of the epithelial cells, or in the goblet cells.

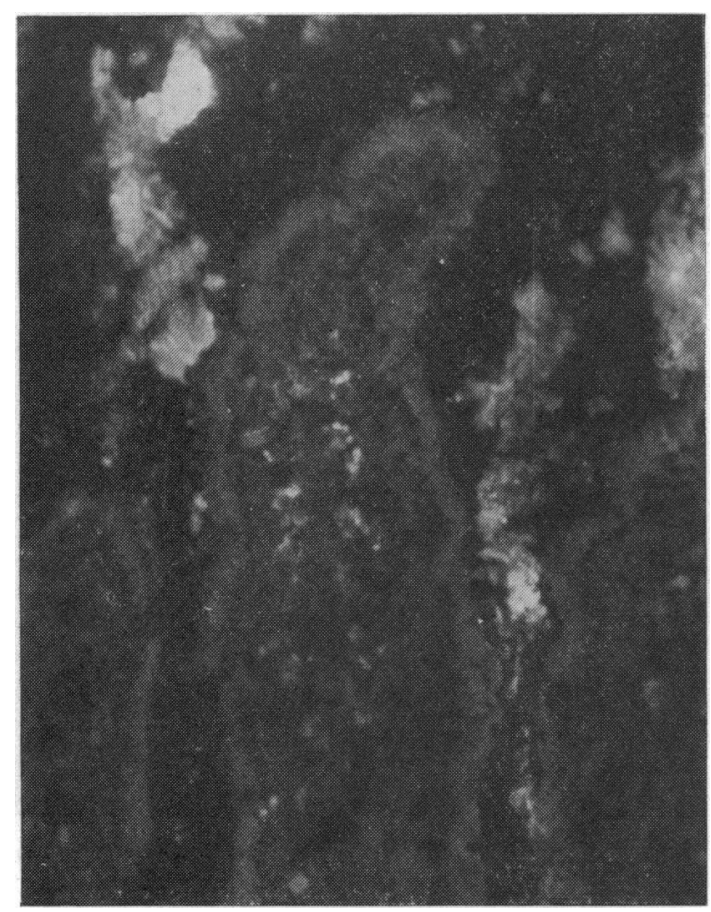

Fig. 3 Duodenum of adult rat 5.5 hours after receiving STI via a stomach tube. The tissue was stained with STI antibody and fuorescent anti-rabbit immunoglobin. Food particles surrounding the villi are strongly fluorescent. $\times 250$.

Adult rats reared on the test or control diets, and then administered STI showed a similar distribution of fluorescence around the villi (Fig. 5). Weakly fluorescent crypt cells were also evident in the ileum and jejunum of some rats in each of these two groups.

Control staining of the various samples in this experiment gave negative results. Likewise, no fluorescence was present in samples taken from rats reared on normal, test, or control diets and then starved or given saline (Fig. 6). In all samples, isolated lymphocytes in the lamina propria of the villi exhibited autofluorescence (Fig. 6).

In suckling rats six hours after administration of STI, the jejunum and particularly the ileum showed positive fluorescence in the lumen and in the epithelial cells of the villi. The fluorescence in these cells extended almost to the base of the villi, but was

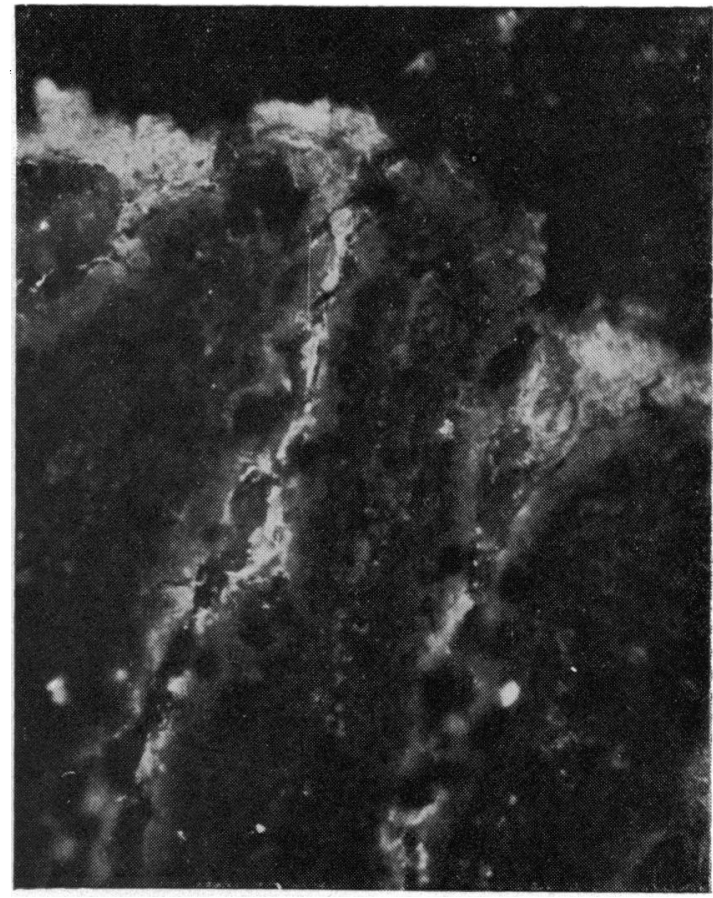

Fig. 4 Ileum of rat treated as in Fig. 3. The fluorescence of the luminal border extends down to the crypt region. $\times 250$.

not detected in the crypt region. In the jejunum the fluorescence was present in numerous small droplets in the apical cytoplasm of the epithelial cells. In the ileum small and large droplets both within the apical cytoplasm and in the supranuclear vacuoles of the epithelial cells showed pronounced fluorescence (Fig. 7). Unlike that in the adult rats, fluorescence was not localised on the brush border of the epithelial cells of the jejunum and ileum.

The specificity of the fluorescence in the suckling rats was confirmed from the negative results obtained by control staining. Fluorescence was also absent in the tissues removed from starved and saline-fed suckling rats (Fig. 8).

\section{Discussion}

The localisation of STI in the epithelial cells of the jejunum and ileum of suckling rats was similar to that described by Clark (1959) for certain other proteins. Such absorption in the rat ceases approximately 18 days after birth (Clark, 1959). At this stage of development, the ability to absorb STI must also presumably be lost, as STI was not detected in the epithelial cells of the adult small intestine. However, the clear immunocytochemical demonstration of 


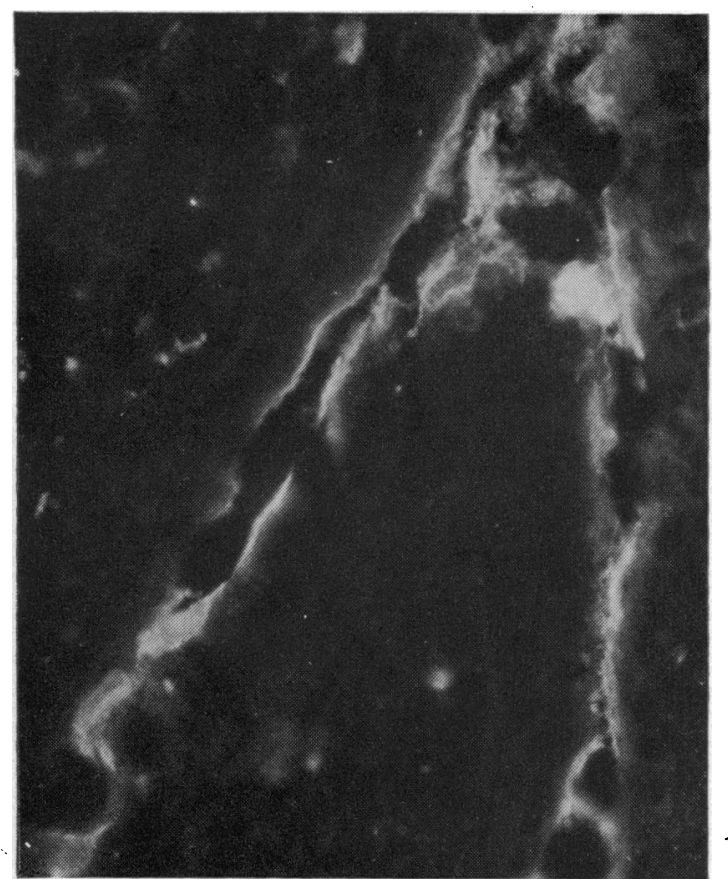

Fig. 5 Fluorescent luminal brush border of villi in ileum. The adult rat had been reared on test diet then fed STI via a stomach tube before staining as in Fig. 3. $\times 400$.

STI in the suckling rat mucosal cells indicates the specificity of the fluorescent reaction and shows that intracellular STI can be visualised in this manner. Moreover, this specificity was confirmed by the absence of fluorescent staining in the intestine of rats on control diets, or those starved or given saline. Likewise, fluorescence was absent in sections treated with antibody which had been preabsorbed with STI.

In adult rats, fluorescence due to the adsorption of STI by the brush border was particularly pronounced in the ileum. This may simply reflect the passage of STI through the intestine, or this region may, in fact, show a preferential adsorption of STI. Previous feeding of STI-containing diets to adult rats did not alter the pattern of fluorescence, which was confined to the lumen and mucosal brush border at all times.

It is conceivable that, in adult rats, STI may be attached via trypsin to the brush border surface, particularly as it has been proposed that pancreatic enzymes, after release and activation, become bound to the surface of mucosal cells (Ugolev, 1965), possibly in preparation for their recirculation by way of the bloodstream and pancreatic acinar cell back into the intestine, as demonstrated recently in the rabbit (Götze and Rothman, 1975). However,

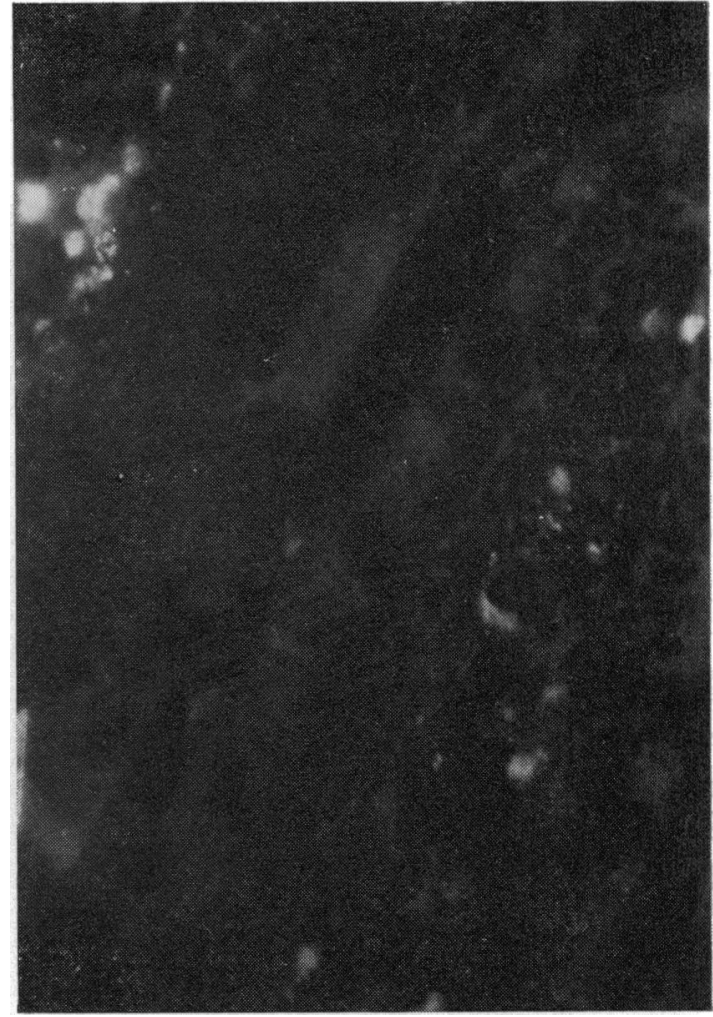

Fig. 6 Ileum of adult rat reared on test diet, and given saline via stomach tube. The tissue was treated with STI-antibody and fluorescent anti-rabbit immunoglobin as for Fig. 3. There is no positive fluorescence in the lumen or around the villi. Lymphocytes in the lamina propria showed autofluorescence. $\times 400$.

Goldberg et al. (1971) have found considerable variation in trypsin adsorption between and within species and, in the case of the rat, could not detect trypsin adsorption by the ileal mucosa. This would suggest that, in the rat, the STI interacts directly, but in some non-specific way, with the lumenal brush border of the small intestine. Which of these two alternatives is the more correct was not further examined in the present study.

The association of STI with the brush border may be essential for its subsequent digestion, particularly as part of the process of protein digestion is thought to occur at this site (Ugolev, 1965; Peters, 1970).

Although the means whereby dietary STI produces pancreatic enlargement is not completely resolved, the present findings suggest that STI does not directly enter the cells of the intestinal mucosa in the adult rat, although the sensitivity of the method used may be insufficient to detect the passage of small but physiologicallv significant amounts of STI into the 


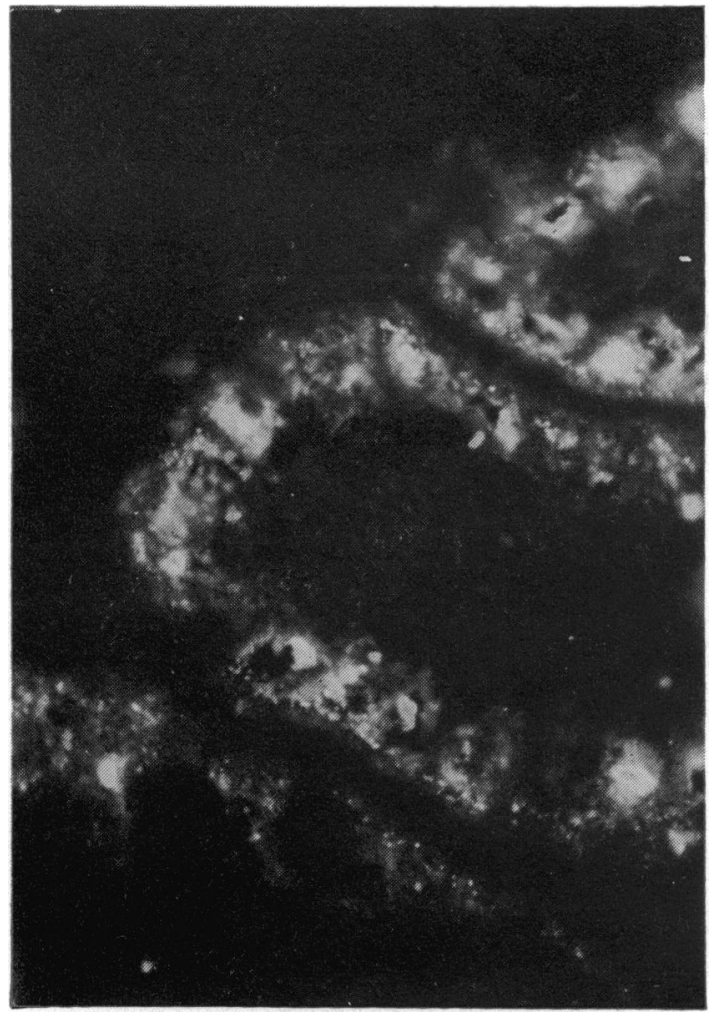

Fig. 7 Ileum of suckling rat six hours after feeding STI followed by fluorescent staining as for Fig. 3. There is pronounced fluorescence in numerous droplets in the apical cytoplasm and in large fluorescent droplets in the supranuclear vacuoles of the epithelial cells. $\times 540$.

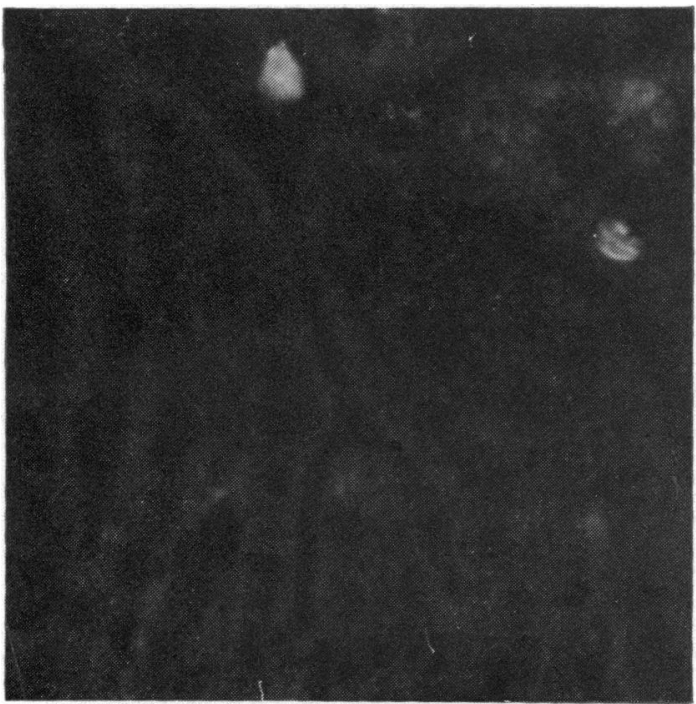

Fig. 8. Ileum of starved suckling rat. The staining procedure was the same as in Fig. 3, but no fluorescence is seen due to the absence of STI in the intestinal tissues. $\times 400$. cells. However, the findings here are consistent with the results of Green and Lyman (1972), who demonstrated that trypsin inhibitors act indirectly on the mucosal cells by binding or neutralising trypsin. In this way the normal inhibitory influence of trypsin on those mucosal cells secreting pancreatrophic hormones is removed and uninhibited hormone secretion results. This hypothesis is further supported by the considerable variation in the molecular size and structure of trypsin inhibitors (Geratz, 1969; Greene and Bartelt, 1969; Koide et al., 1972) which produce this effect on the pancreas, making unlikely a specific cell surface receptor/trypsin inhibitor interaction either in the intestinal mucosa or in the pancreas. Indeed, the only characteristic feature common to the wide variety of synthetic and naturally occurring trypsin inhibitors which have been shown to produce pancreatic enlargement in the rat and chicken is their ability to inhibit trypsin.

This work was supported by grants from the Medical Research Council and the Wellcome Trust.

\section{References}

Booth, A. N., Robbins, D. J., Ribelin, W. E., and DeEds, F. (1960). Effect of raw soybean meal and amino acids on pancreatic hypertrophy in rats. Proceedings of the Society for Experimental Biology and Medicine, 104, 681-683.

Clark, S. L. Jr (1959). The ingestion of proteins and colloidal materials by columnar absorptive cells of the small intestine in suckling rats and mice. Journal of Biophysical and Biochemical Cytology, 5, 41-50.

Cornell, R., and Padykula, H. A. (1969). A cytological study of intestinal absorption in the suckling rat. American Journal of Anatomy, 125, 291-315.

Fisher, R. B. (1967). Absorption of proteins. British Medical Bulletin, 23, 241-246.

Geratz, J. D. (1969). Secretory stimulation of the rat pancreas by p-aminobenzamidine. American Journal of Physiology, 216, 812-817.

Goldberg, D. M., Campbell, R., and Roy, A. D. (1971). The interaction of trypsin and chymotrypsin with intestinal cells in man and several animal species. Comparative Biochemistry and Physiology, 38, 697-706.

Götze, H., and Rothman, S. S. (1975). Enteropancreatic circulation of digestive enzyme as a conservation mechanism. Nature, 257, 607-609.

Green, G. M., and Lyman, R. L. (1972). Feedback regulation of pancreatic enzyme secretion as a mechanism for trypsin inhibitor-induced hypersecretion in rats. Proceedings of the Society for Experimental Biology and Medicine, 140, 6-12.

Greene, L. J., and Bartelt, D. C. (1969). The structure of the bovine pancreatic secretory trypsin inhibitor-Kazal's inhibitor. II. The order of the tryptic peptides. Journal of Biological Chemistry, 244, 2646-2657.

Hill, R. J. (1972). Elution of antibodies from immunoabsorbents: effect of dioxane in promoting release of antibody. Journal of Immunological Methods, 1, 231-245.

Khayambashi, H., and Lyman, R. L. (1969). Secretion of rat pancreas perfused with plasma from rats fed soybean trypsin inhibitor. American Journal of Physiology, 217, 646-651. 
Koide, T., Tsunasawa, S., and Ikenaka, T. (1972). The amino acid sequence of soybean trypsin inhibitor (Kunitz). Journal of Biochemistry (Tokyo), 71, 165-167.

Lyman, R. L., and Lepkovsky, S. (1957). The effect of raw soybean meal and trypsin inhibitor diets on pancreatic enzyme secretion in the rat. Journal of Nutrition, 62, 269-284.

Melmed, R. N., and Bouchier, I. A. D. (1969). A further physiological role for naturally occurring trypsin inhibitors: the evidence for a trophic stimulant of the pancreatic acinar cell. Gut, 10, 973-979.

Melmed, R. N., El-Aaser, A. A., and Holt, S. J. (1976). Hypertrophy and hyperplasia of the neonatal rat exocrine pancreas induced by orally administered soybean trypsin inhibitor. Biochimica et Biophysica Acta, 421, 280-288.

Nairn, R. C. (1969). Fluorescent Protein Tracing, pp. 304-305. Livingstone: Edinburgh.
Ouchterlony, Ö. (1968). Handbook of Immunodiffusion and Immunoelectrophoresis, pp. 21-47. Ann Arbor Science: Ann Arbor, Michigan.

Peters, T. J. (1970). Intestinal peptidases. Gut, 11, 720-725.

Porath, J., Axén, R., and Ernback, S. (1967). Chemical coupling of proteins to agarose. Nature, 215, 1491-1492.

Rackis, J. J. (1965). Physiological properties of soybean trypsin inhibitors and their relationship to pancreatic hypertrophy and growth inhibition of rats. Federation Proceedings, 24, 1488-1493.

Ugolev, A. M. (1965). Membrane (contact) digestion. Physiological Reviews, 45, 555-595.

Warshaw, A. L., Walker, W. A., and Isselbacher, K. J. (1974). Protein uptake by the intestine: evidence for absorption of intact macromolecules. Gastroenterology, 66, 987-992. 